\title{
"EU QUERO [OUVIR] DE NOVO!": O ENVOLVIMENTO CRIATIVO DE CRIANÇAS DE 5 ANOS NA MUSICALIZAÇÃO INFANTIL
}

\author{
"I want [to hear] it again!": 5-year-old \\ children's creActive involvement in music \\ education
}

\author{
"Yo quiero [escuchar] de nuevo!": el \\ envolvimiento creActivo de niños de 5 años \\ en la educación musical infantil
}

\author{
Tiago Madalozzo \\ Universidade Estadual do Paraná \\ tiago.madalozzo@unespar.edu.br
}

\begin{abstract}
Resumo: O tema deste artigo é o envolvimento musical de crianças de 5 anos de idade em atividades de musicalização infantil. Busca-se discutir e definir os aspectos que configuram as diferentes situações de envolvimento de uma turma de crianças participantes de atividades de musicalização em uma escola especializada. Por meio de um estudo etnográfico educacional, chega-se à definição do envolvimento musical em dois sentidos: musicais e sociais. Em um diálogo com a literatura, esses sentidos são expandidos a partir da apresentação dos conceitos de criAtividade e de autonomia musical infantil. Conclui-se que o envolvimento das crianças na musicalização colabora com uma aprendizagem musical significativa, e configura o olhar do adulto-professor em relação às crianças enquanto criAtivas agentes de construção de seu mundo musical, a partir de uma relação em que crianças e professores jogam-se na e pela música.
\end{abstract}

Palavras-chave: Educação musical infantil. Musicalização. Criatividade musical.

Abstract: This text aims to discuss the idea of music involvement by 5-year-old children who participate in an early childhood music education program at a music school. The goal is to understand the aspects that define this musical involvement. A case study is described through an educational ethnographic approach, pointing out two definitions of the music engagement: a musical and a social meanings. These ideas lead the theoretical discussion, in a dialogue between the definitions of autonomy and creActivity in music education. The main conclusion is that the musical involvement defines a significant process of music learning, and at the same time shapes the adult-teacher's comprehension of children as creActive agents in their relations with the musical universe around them.

Keywords: Early childhood. Music education. Musical creativity.

Resumen: El tema de este texto es la participación musical de niños de 5 años en actividades musicales. Lo que se analiza es un grupo de niños que participan en actividades de educación musical en una escuela especializada. Se busca discutir y definir los aspectos que configuran las diferentes situaciones de envolvimiento de estos niños en las actividades. A través de una investigación etnográfica educacional, se llega a la definición de envolvimiento musical en dos sentidos: musical y social. En un diálogo con la bibliografia, estos significados se amplian a partir de la presentación de los conceptos de creActividad y de autonomía musical de los niños. Se concluye que el envolvimiento de los niños en la educación musical contribuye a un aprendizaje musical significativo, y configura la mirada del docente adulto con relación a los niños como agentes creativos de construcción de su mundo musical, a partir de una relación en la que niños y docentes se juegan en y con la música.

Palabras clave: Educación infantil. Educación musical. Creatividad musical. 


\section{INTRODUÇÃO}

Um grupo "muito envolvido": era a forma como as professoras, a coordenadora e os pais de seis crianças com 5 anos de idade descreviam aquela turma de musicalização infantil. Afinal, o que poderia caracterizar o envolvimento no aprendizado de música nessa idade? Essa foi a pergunta que moveu a investigação que é relatada neste artigo, que tem como tema a discussão dos aspectos que definem as diferentes maneiras pelas quais as crianças se relacionam com a música em uma escola especializada.

A musicalização infantil é um processo de sensibilização sonora no qual a criança passa a atribuir sentido aos conceitos musicais a partir de uma série de práticas ativas em que se envolve de maneira(s) significativa(s) (Brito, 1998; Gainza, 1982; Madalozzo, 2019b; Penna, 2008). Como resultado, há um evidente processo não só de ensino/aprendizagem, mas que envolve também a construção de uma importante relação das crianças umas com as outras e com os adultos-professores.

A partir dessas definições, a questão inicial se desmembra em outras perguntas: como discutir e compreender o envolvimento musical das crianças em atividades de musicalização; como compreender o sentido musical do envolvimento das crianças; e como entender o sentido social do processo de aprendizagem na musicalização? O objetivo é discutir e definir esses aspectos que configuram as diferentes situações de envolvimento das crianças nas aulas de música.

Este artigo é uma trama encadeada a partir de dois fios: um diálogo inicial com o referencial teórico, examinando os aspectos musicais e os aspectos sociais ligados ao envolvimento das crianças na musicalização; e um segundo fio, originado de dados encontrados no campo empírico a partir de observações de aulas com o grupo de crianças em um novo diálogo com a teoria, definindo os conceitos de criAtividade e de autonomia musical. Ao final, a trama desses dois diálogos torna viável melhor compreender o envolvimento das crianças na musicalização.

O estudo relatado faz parte de uma investigação mais ampla, apresentada inicialmente em forma de tese de doutorado. ${ }^{1}$

\section{DIÁLOGO INICIAL: OS SENTIDOS MUSICAIS E SOCIAIS DO ENVOLVIMENTO NA MUSICALIZAÇÃO}

Esta investigação parte da ideia de que o envolvimento das crianças na musicalização é um conceito que pode ser segmentado em dois menores: os aspectos sociais e os aspectos musicais envolvidos nesse processo. A partir dessa ação de segmentação, os dois conceitos serão definidos e, mais à frente,

\footnotetext{
1 Este artigo foi ampliado e revisado a partir de comunicação realizada nas IV Jornadas em Estudos da Criança do Instituto de Educação da Universidade do Minho, Portugal, em julho de 2019 (ver Madalozzo, 2019a).
} 
ressignificados e reintegrados a partir de novas reflexões frente aos dados encontrados no campo.

A revisão teórica inicial dos aspectos musicais da musicalização demonstra que o conceito de musicalização infantil, enquanto processo de aprendizagem significativa em música, pode ser ampliado com dois princípios que o fundamentam: o de atividade e o de criatividade, no entendimento das pedagogias ativas de educação musical. Para autores como Gainza (1982, 2003), Delalande (1984) e Fonterrada (2008), nas primeiras décadas do século passado houve uma mudança de paradigma em relação ao foco pedagógico da educação musical, passando da música em si (objeto) para a criança que faz música (sujeito). Essa mudança de foco leva ao conceito de atividade: o ensino pautado na prática da música como uma forma de expressão múltipla, em que a criança atua com seu corpo em movimento, na dança, na linguagem, na música em si e em múltiplas expressões artísticas.

A atividade leva ao conceito de ludicidade, enquanto elemento de envolvimento da criança com o mundo que a cerca, incluindo o jogo, que Delalande (1984) afirma ser característica desse relacionamento da criança com a música. A atividade e a ludicidade conduzem a uma primeira definição de envolvimento musical: a conexão das crianças com a música a partir da vivência lúdica e da experiência. Um exame das pedagogias ativas de educação musical (como as de Orff, Dalcroze, Kodály, Martenot, Willems, Suzuki) mostra ainda que nelas há princípios comuns ligados ao conceito de atividade que também se conectam à ideia de musicalização: o ensino da música desde cedo na vida das crianças; direcionado a todas, sem exceção; em que se chega às compreensões teóricas ou técnicas sempre a partir da prática; buscando a expressividade; e tendo foco na criança como sujeito que faz música nesse processo. Em suma, a musicalização aparece como uma oportunidade privilegiada de experiência e de compreensão musical para as crianças, satisfazendo seu "apetite musical", nas palavras de Delalande (1984, p. 15).

Por outro lado, o conceito de criatividade proposto pelos educadores musicais das pedagogias ativas de educação musical envolve propostas musicais de improvisação, composição e interpretação direcionadas às crianças, mas determinadas pelos próprios professores: nesse sentido, as crianças podem expressar-se musicalmente, desde que dentro de parâmetros musicais predefinidos pelos adultos. ${ }^{2}$ As pedagogias criativas de educação musical (como

\footnotetext{
2 Gainza (1982, p. 98-100) discute o fato de que nas primeiras décadas do século XX as pedagogias ativas de educação musical destacavam o valor educativo do jogo musical a partir da aplicação de um novo conceito de criatividade, se comparado ao ensino "mecânico e impessoal" que caracterizava o ensino tradicional de música. Por outro lado, a partir da segunda metade do século, a exploração da matéria sonora na música e as descobertas científicas, psicológicas, sociológicas e artísticas levaram a ainda uma nova definição de criatividade, entendida como princípio de liberdade e expressão musical. A partir deste raciocínio, Gainza (1982, p. 100-105) justifica que as pedagogias ativas traziam exemplos "prontos para o consumo" pelos "grandes metodologistas", ou seja, tendo uma abertura criativa estabelecida e limitada ao olhar do educador, e não com protagonismo das crianças; já a nova definição de criatividade se refere à abertura de "novas perspectivas" na estimulação e no desenvolvimento da capacidade criadora das crianças, que é o que caracteriza as pedagogias criativas de educação musical.
} 
as de Meyer-Denkmann, Paynter, Self, Schafer, Koellreutter) se definem a partir de uma nova mudança de foco: da atividade para a criatividade, em um sentido de descoberta, experimentação, investigação, liberdade das crianças no contato com o universo sonoro, em um movimento de integração, síntese, troca coletiva (Gainza, 1982, 2003); em outras palavras, um modo de contato com a música em que as crianças jogam com e jogam-se na música (Gainza, 1982, p. 100). O conceito de criAtividade, que mais tarde será utilizado neste texto, está relacionado não apenas a atividades musicais de improvisação e de composição, mas também à experimentação sonora e à construção musical em atividades de execução e de escuta ativa - todo um ciclo de possibilidades de envolvimento da criança com música, em um exercício que compartilham, como protagonistas, com os professores-orientadores.

É desse modo que o foco de investigação passa para os aspectos sociais do envolvimento na musicalização. Partindo do conceito de infância(s) e de cultura(s) da infância da área da sociologia da infância, entende-se que tais culturas são constituídas socialmente pelas crianças, tendo como um de seus pilares a ludicidade enquanto condição de aprendizagem da sociabilidade a partir do brinquedo e do brincar. As culturas da infância são definidas pelas trocas realizadas pelas crianças em suas interações entre pares e com o mundo adulto, levando em consideração sua participação nas rotinas das culturas de pares e nas rotinas adulto-criança, como acontece na formação musical. A infância é entendida como uma componente sociocultural complexa, de um lado pela alteridade configurada com o mundo adulto, e de outro pela agência da criança na interpretação e na modificação, com seus próprios meios, dessa relação como o outro, através da ludicidade (Corsaro, 2011; Sarmento, 2004).

Considerando que nesta pesquisa o foco de análise é um modelo de trabalho em aulas planejadas e conduzidas pela figura do adulto-professor, ali ocorre um processo de instrução que implica a transmissão intencional de conhecimentos. Por isso, as questões sociais do envolvimento abrangem das teorias da psicologia, com o conceito de zona de desenvolvimento iminente (ZDI) proposto por Vigotski (1998a; 1998b) e ampliado em tradução de Prestes (2010). Nesse sentido, há o nivel de desenvolvimento atual ou real da criança, com tudo aquilo que hoje está amadurecido, e o desenvolvimento iminente, ou seja, os processos que se encontram a caminho do amadurecimento, e que amanhã poderão ou não passar para o nível de desenvolvimento atual: se trata de um campo de possibilidades de desenvolvimento, a partir da interação colaborativa da criança com seus pares e com os adultos.

Esse ponto se liga ao conceito de gestão na aula de música, segundo o qual a aprendizagem musical das crianças poderá ou não ocorrer a partir da condução de práticas pelo professor em que haja um equilíbrio entre um ambiente musical desafiador e gratificante e os interesses e capacidades das crianças: a balança entre os desafios e as habilidades que pode determinar o grau de envolvimento das crianças com música (Koops, 2018; Russell, 2005).

Em suma, neste primeiro diálogo com a teoria, o envolvimento das crianças na musicalização parte de um contato ativo e criativo com a música, em 
posição de protagonismo em suas produções com os pares e com a orientação do adulto-professor, a partir da estruturação de um ambiente rico musicalmente e de propostas adequadas e desafiadoras em relação às habilidades das crianças.

\section{O ESTUDO DE CASO: UMA TURMA “MUITO ENVOLVIDA” NA MUSICALIZAÇÃO}

Para tecer uma trama com o fio do primeiro diálogo teórico, esta investigação lança mão de um estudo de caso realizado a partir de um desenho metodológico que envolve a etnografia educacional.

O caso de uma turma de crianças no curso de música é uma situação específica e significativa para o tema pesquisado (André, 2012; Penna, 2015), sendo que a descrição e a transcrição dos dados encontrados no campo empírico tornam viável a formulação de conceitos, abstrações, teorias. Essa foi a justificativa da escolha do estudo de caso etnográfico educacional, abordagem em que a investigação se dá por meio da observação participante e da análise de documentos para interagir com a situação estudada, e para contextualizar e complementar os fenômenos observados. Em outras palavras: a partir da descrição pormenorizada, chegar a explicações teóricas, em busca do conhecimento por trás de observações isoladas (André, 2012; Walsh, 2003). Por isso, Ezpeleta e Rockwell (1989) consideram fundamental a compreensão de que o fenômeno estudado é um processo particular dentro de uma totalidade social.

Nesse tipo de pesquisa, a observação participante é usada como ferramenta de coleta de dados a partir do entendimento de que há uma dialética constante entre a experiência e a interpretação para o investigador, em um processo de vaivém do interior ao exterior dos acontecimentos. Por isso é necessário registrar gestos, palavras, sons (experiência: no interior), mas ao mesmo tempo situar esses significados em contextos mais amplos (interpretação: do exterior) (Clifford, 2011). As anotações do diário de campo fazem parte de um exercício de tradução, na medida em que a interpretação do investigador acontece ao mesmo tempo que são feitos os registros "a quente" da situação estudada (Ferreira, 2004, p. 52). Outro ponto de destaque é que, na observação, é importante reconhecer a existência de diversas vozes presentes no campo da pesquisa: a verbal, a sonora e todas as outras formas de expressão infantil (Marchi, 2018), de modo que o registro de observação vai muito além da anotação da fala das crianças.

O campo empírico da investigação foi a escola de música Alecrim Dourado Formação Musical, na cidade de Curitiba, que tem 11 anos de funcionamento e atende crianças de 0 a 10 anos de idade divididas em turmas de musicalização infantil. As aulas semanais são em grupo, com duração de 50 minutos para crianças até completarem 5 anos de idade, e de 1 hora e 15 minutos para as maiores. As crianças são divididas pela faixa etária e participavam das atividades com uma dupla de professores por turma à época da 
investigação. Todos os professores têm formação superior e/ou pós-graduação na área de educação musical. ${ }^{3}$

A proposta pedagógica da escola é fundamentada no contato musical ativo desde cedo na vida das crianças, a partir de um trabalho de sensibilização auditiva e musical. Subordinada a essa proposta geral está o documento intitulado Descritivo curricular, em que se determinam os conteúdos e objetivos de cada um dos quatro níveis de formação musical no curso. No Descritivo curricular, à época da investigação as crianças de 5 a 7 anos de idade integravam o Grupo Pré-Instrumental, terceiro nivel de formação, depois da Musicalização Infantil (0 a 1 ano e 11 meses) e da Iniciação Musical (2 a 4 anos e 11 meses). O Grupo Pré-Instrumental tem por objetivo a vivência de propostas musicais em grupo vocal e instrumental, desenvolvendo habilidades que dão uma base comum para o estudo futuro de qualquer instrumento musical pela criança. As estratégias incluem a leitura ritmica e a melódica baseadas na escrita musical tradicional; a experimentação de instrumentos musicais de diferentes famílias, explorando e tocando instrumentos de percussão com ênfase no instrumental Orff e nos princípios básicos da flauta doce; o canto, evidenciando a precisão das alturas e da afinação; a execução e a criação de pequenas músicas e arranjos; e a audição musical ativa a partir do uso de gráficos e da escrita musical não tradicional, a fim de possibilitar a compreensão da organização formal de diferentes repertórios (Musicalização..., 2019, p. 1).

As crianças até os 2 anos de idade frequentam as aulas juntamente com um adulto (um dos pais ou um cuidador) para mediar a realização das atividades. A partir dessa idade, ficam em sala apenas com as outras crianças e a dupla de professores, enquanto os cuidadores acompanham a realização das atividades por meio de uma televisão na recepção da escola, em que são transmitidas imagens captadas em tempo real na sala de aula. Duas vezes ao longo do semestre letivo, nas semanas central e final do calendário, realizam-se aulas abertas para a família, quando os pais ou cuidadores das crianças são convidados a participar da aula para acompanhar presencialmente o processo de construção musical feito com as crianças. Cada semestre letivo tem um tema gerador das atividades musicais em aula, e nesse caso o tema foi o rock'n'roll.

Os participantes do estudo foram seis crianças com 5 anos de idade, integrantes de uma turma de musicalização do Grupo Pré-Instrumental, que tiveram aulas no segundo semestre letivo do ano de 2018 (de agosto a dezembro), ao longo de 18 semanas de aulas (período de realização das observações). Das seis crianças participantes na turma, uma estava matriculada no curso de musicalização há nove semestres; duas, há oito semestres; uma, há sete; uma, há seis; e apenas uma, há um semestre. De todas, cinco delas já

\footnotetext{
3 O pesquisador foi professor da escola durante sete anos e, apesar de não atuar mais na instituição no momento de realização do estudo, o contato prévio com os participantes (professores, crianças e seus cuidadores) foi um meio facilitador da entrada no campo.
} 
faziam aulas com o mesmo grupo de crianças há dois semestres letivos, com a orientação da mesma dupla de professoras. Estas trabalham na escola desde 2013, sendo as professoras há mais tempo na equipe. Os dados evidenciam que havia um vínculo significativo entre as crianças da turma e as professoras e também entre as crianças e a escola: em alguns casos, por mais da metade de seu tempo de vida.

Para a coleta de dados, observou-se as crianças atuando nas salas de aula. O pesquisador se posicionou em um dos cantos do espaço, observando as trocas de olhares, a movimentação, os diálogos e as interações musicais entre elas e as professoras, sem interferir na realização das atividades. As anotações foram feitas em um caderno de campo usando simbolos e abreviações de modo a proporcionar o maior tempo possivel de contato visual (e auditivo) com as crianças. As transcrições foram feitas em seguida. Também foram realizadas gravações em vídeo aproveitando o equipamento de transmissão de imagens da escola, mas essa fonte de dados foi posteriormente descartada, considerando-se que os dados levantados a partir das anotações do caderno de campo foram suficientes para as descrições propostas na compreensão do estudo.

Os registros em sala foram organizados em episódios, extrapolando a ideia de "episódios interativos" de Corsaro (1979), por incluírem situações de envolvimento musical que muitas vezes ultrapassavam apenas um diálogo ou produção musical das crianças, se estendendo por vários minutos e englobando diferentes personagens. ${ }^{4} \mathrm{O}$ objetivo desse agrupamento de situação menores em episódios amplos foi permitir uma visão macro dos acontecimentos, descrevendo as práticas no contexto de cada aula, seja por uma questão de gestão da aula, ou pelo olhar analítico de investigação, já no momento de transcrição.

\section{O QUE AS CRIANÇAS TÊM A EXPRESSAR: DIÁLOGOS NO CAMPO EMPÍRICO E ANÁLISES INICIAIS}

Foram 20 os episódios analisados na investigação, e a Figura 1 reúne esquemas artísticos que foram produzidos a partir de quatro deles. A seleção apresentada abaixo reúne trechos editados do caderno de campo referentes aos episódios 1 e 4 das duas primeiras aulas do semestre letivo. Na aula 1, Gabriel, Nicole, Luna, Marcela e Lara (nomes fictícios para preservar o anonimato) chegam à sala de aula e veem objetos no chão. As professoras orientam a execução, a apreciação e a improvisação com pouco uso de comandos verbais, no episódio 1:

\footnotetext{
4 Segundo Corsaro (1979, p. 47), um episódio interativo se refere a uma sequência de ações que se inicia com a presença de dois ou mais participantes em uma área específica, com as tentativas de se chegar a um acordo na emergência de uma atividade, e que finaliza com o movimento físico dos participantes a partir dessa área, tendo como resultado o término de tal atividade.
} 
As crianças tiram os sapatos e se aproximam de uma roda com oito baldes verdes no chão, virados de cabeça para baixo. Se sentam em volta dos baldes e começam a tocar e manipular os objetos com as mãos, com os cotovelos, presos na cabeça, ou servindo de bancos. A professora Alice diz: "Vamos imitar", e propõe algumas frases rítmicas com combinações de palmas e batidas com as mãos nos baldes, que as crianças imitam. Nos intervalos das frases, propõe improvisos; depois, vai incorporando em suas próprias frases as criações das crianças. A professora Rosane chega à sala, enquanto Alice se levanta e liga a música Smoke on the water [canção da banda Deep Purple, de 1972] no rádio. As professoras não falam nada, mas as crianças começam a tocar, olhando para as adultas, que gradativamente sincronizam as batidas no padrão inicial, entre palmas e baldes. Quando chega a estrofe, Alice fala forte: "Improvisa!", e todos batucam sem um ritmo pré-definido. Lara experimenta, tocando com os punhos fechados. Marcela inicialmente põe o balde na cabeça; ao perceber que Lara consegue sons interessantes, experimenta também, e acaba tocando com as unhas e pontas de dedos. Quando chega o terceiro refrão, depois do segundo improviso, todos já entram no riff [padrão rítmico característico] da música na primeira tentativa. [Caderno de campo, aula 1] (Madalozzo, 2019b, p. 64-65).

A segunda parte do episódio 1 se passa em outro momento da aula, quando as crianças estão sentadas no chão em torno de uma roda com xilofones sem baquetas. A prática instrumental tem ligação com o repertório inicialmente apresentado:

As crianças se aproximam de uma roda de xilofones no chão, ainda sem baquetas disponiveis, em frente aos quais se sentam. Rosane orienta que elas tirem as plaquetas, deixando apenas as notas si, ré, mi e fá. Rosane, em silêncio, mostra com o dedo indicador da mão direita uma sequência de notas, encostando no seu xilofone. Todos param para olhar. Rosane repassa o riff, falando os nomes das notas: si ré mi (pausa), si ré fá mi. Alice toca o riff no violão algumas vezes enquanto as crianças experimentam imitar a frase. Depois de algumas repetições, Rosane mostra com os dedos a segunda frase: si ré mi (pausa), ré si si. Marcela imita e acerta na primeira tentativa: diz "Consegui, yes!”. Rosane distribui uma baqueta para cada criança, dizendo "Agora com baquetas". Alice dá um comando verbal e todos começam a tocar. Rosane vai orientando a execução de cada um individualmente, até que todos tocam juntos. Por fim, Alice comanda uma última repetição e dita o ritmo da música apenas acompanhando no violão, sem usar comandos verbais. [Caderno de campo, aula 1] (Madalozzo, 2019b, p. 65). 


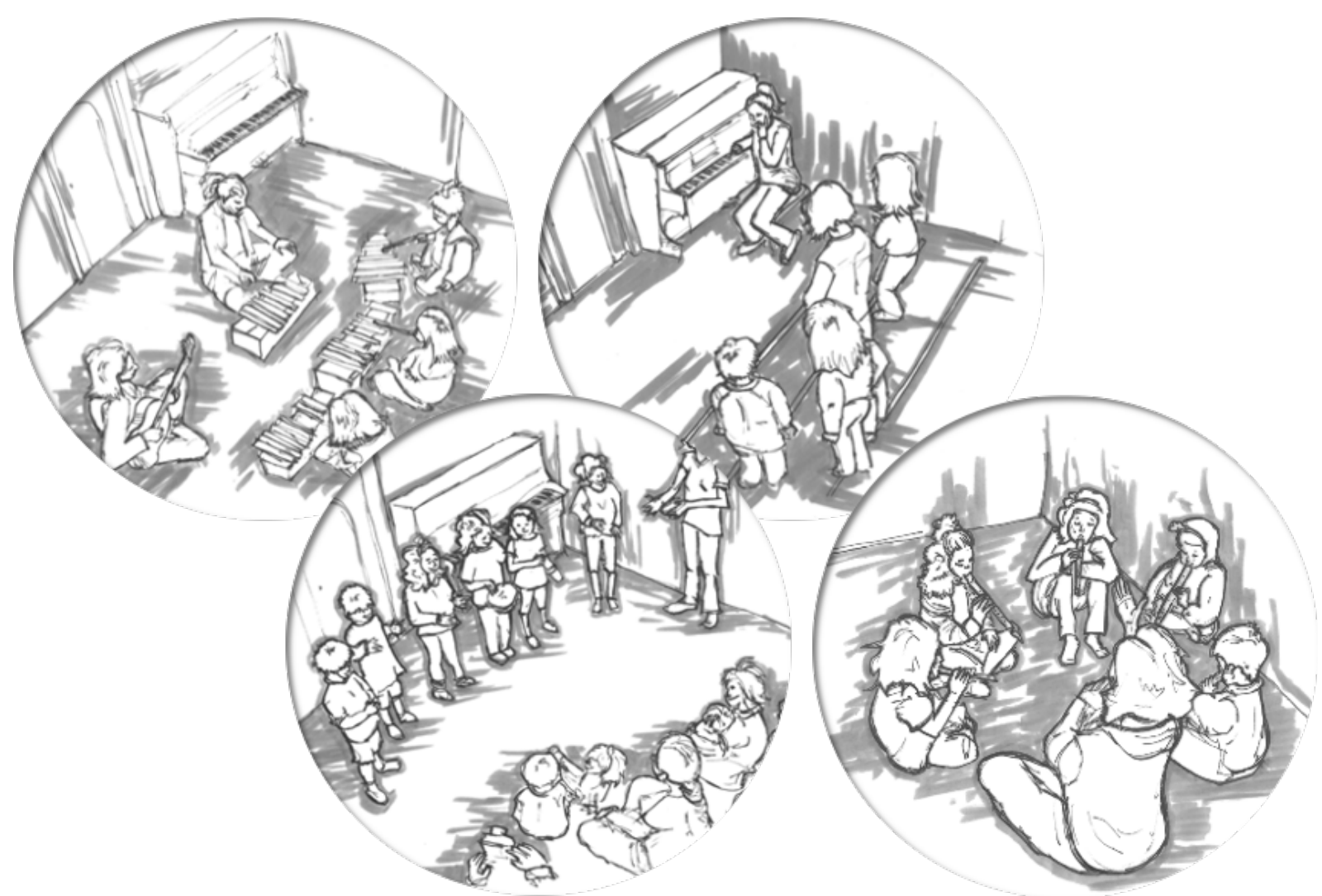

Figura 1: Esquemas artísticos de quatro episódios selecionados: prática instrumental com xilofone, atividade de percepção sonora com movimento, aula aberta e prática instrumental com flauta doce - desenhos de Nisiane Madalozzo.

Fonte: adaptado de Madalozzo (2019b, p. 67, 75, 80, 89).

Já o episódio 4, agora na aula 2, inclui um arranjo musical mais complexo com a frase musical rítmica e melódica praticada na aula anterior:

$\mathrm{Na}$ segunda aula do semestre, Rosane orienta as crianças a arrumarem a ordem das plaquetas nos xilofones, repassando em seguida o riff de Smoke on the water. Enquanto Gabriel, Marcela e Nicole vão se lembrando da frase com Rosane, Alice orienta Sofia e Jorge [nomes fictícios], que não haviam participado da aula anterior. Após algumas repetições, todos tocam juntos. Rosane então diz "E que tal se, em outra aula, a gente trouxer uma guitarra para tocar essa música?", a que Marcela responde "Uhúuuu!" e Sofia diz "E a bateria?". Rosane responde "Que tal?!", e Sofia rola no chão, demonstrando contentamento. Rosane diz "Hoje fizemos na outra aula uma bateria de baldes", e monta uma bateria com 5 baldes virados de cabeça para baixo, um tambor no meio, e pandeiretas em cima de dois dos baldes. Gabriel diz "Precisa de duas baquetas!". Rosane convida todos a experimentar. Nicole, Gabriel, Sofia e Jorge tocam. Jorge toca pouco e desiste, encabulado. Marcela diz que não quer tocar. Enquanto isso, Nicole retorna à bateria e toca, per- 
cutindo os baldes com as baquetas, e ao mesmo tempo dizendo "Si ré mi, si ré fa miiiii!" [a frase da atividade anterior, no xilofone]. [Caderno de Campo, aula 2] (Madalozzo, 2019b, p. 68).

Por meio da seleção e da ordenação desses e de outros 18 episódios, foram levantados 12 temas a partir de um mesmo questionamento: em cada situação, o que caracterizava o envolvimento musical das crianças? Os temas foram então agrupados em duas categorias, considerando que seis deles eram ações que partiam das crianças, e outros seis, de ações das adultas-professoras. Entre as ações das crianças, o envolvimento apareceu pela exploração sonora, pela conexão com o material musical ou com o repertório, pela criatividade musical, pelo entendimento da ordem da aula, pelo encantamento na apresentação de novos instrumentos e pelo interesse em participar. Entre as ações das adultas, o envolvimento apareceu pela variedade de abordagens usadas para encorajar a participação das crianças, pela orientação nos momentos de dificuldade, pela valorização da criatividade musical das crianças, pelo trabalho em grupo, pela proposta de novos desafios e pelo respeito à expressão individual.

Essa etapa de tematização foi importante na análise a fim de compreender a abrangência do(s) entendimento(s) de envolvimento na musicalização. No Quadro 1 aparecem os dados levantados sobre os dois episódios descritos neste relato, que fizeram parte das aulas 1 e 2 . Na terceira coluna estão os temas que foram observados em cada um dos episódios, agrupados entre as duas categorias de análise iniciais: ações das crianças e ações das adultas.

\begin{tabular}{|c|c|c|c|}
\hline Episódio & Aula & \multicolumn{2}{|c|}{ Temas } \\
\hline 01 & 01 & $\begin{array}{c}\text { Ações das crianças } \\
\text { ou com o repertório } \\
\text { Criação musical } \\
\text { Interesse em participar }\end{array}$ & $\begin{array}{c}\text { Variedade de abordagens } \\
\text { Valorização da criatividade } \\
\text { Trabalho em grupo }\end{array}$ \\
\hline 04 & 02 & $\begin{array}{c}\text { Exploração sonora } \\
\text { Encantamento } \\
\text { Conexão com o material musical }\end{array}$ & $\begin{array}{c}\text { Respeito à expressão individual } \\
\text { Variedade de abordagens }\end{array}$ \\
\hline
\end{tabular}

Quadro 1: Temas associados aos dois episódios.

Fonte: adaptado de Madalozzo (2019b, p. 92).

A partir desse exemplo, fica evidente a primeira proposta de análise, considerando que o envolvimento englobava questões de gestão e planejamento das professoras, e sob o olhar das crianças, sua estreita relação com o ambiente sonoro nas aulas. As categorias de análise, nessa proposta, eram: as ações das crianças e as ações das adultas. Por outro lado, um exame mais atento a essa primeira categorização pareceu definir o envolvimento apenas em função das ações que aconteciam entre as crianças e a música, ou entre 
as adultas e a música, dando margem para a interpretação de que o processo de musicalização não era integrado entre os participantes. Essa visão não correspondia ao verdadeiro processo musical e social que caracteriza a musicalização; por isso, foi preciso ampliar o olhar analitico.

Como solução, o olhar inicialmente longitudinal foi deslocado para uma nova orientação transversal, considerando as relações entre os agentes (crianças e adultas) e a música. Por essa razão, depois do exame detalhado dos diálogos no campo empírico é que emergiram dois conceitos teóricos para compreendê-los: os sentidos musicais e os sentidos sociais do envolvimento das crianças na musicalização.

A ideia de envolvimento passou a ser definida a partir desses dois sentidos: do ponto de vista musical, se trata da relação das crianças com a música, em um processo mediado pelas adultas; do ponto de vista social, se trata das interações entre as crianças e as adultas, mediadas pela música. Esses dois conceitos se mostraram consonantes com a revisão teórica apresentada na seção anterior deste artigo. Por outro lado, tendo em vista todos os achados em campo, foi necessário retornar à literatura acadêmica para novos diálogos, com as ideias de sentidos musicais e sociais do envolvimento em mãos, para melhor os definir.

\section{UM NOVO DIÁLOGO INCLUINDO A LITERATURA}

"Eu quero [ouvir] de novo!", diz Gabriel ainda na primeira aula do semestre, quando termina a execução no rádio da canção Hello goodbye, do grupo The Beatles, de 1967. Em outra aula, Marcela responde com grande felicidade, "Uhúu!", e Sofia demonstra muita alegria, quando as professoras trazem uma guitarra e uma bateria feita de baldes e garrafões para as crianças experimentarem e tocarem o repertório que começam a construir em conjunto, em uma pequena banda. $\mathrm{Na}$ aula 4, Luna, a criança mais introvertida da turma, surpreende a todos e sai da sala com um pequeno metalofone, totalmente concentrada em tocar diversas vezes o riff de Iron man, canção da banda Black Sabbath de 1971, indo em direção à recepção, onde é aplaudida pelos pais das crianças. Na última aula do semestre, após dois meses de contato inicial com a flauta doce soprano, as crianças apresentam a seus pais, orgulhosas, a composição que criaram em conjunto, usando duas notas na flauta (si e lá), que tocam afinadamente, e os ritmos que aprenderam no semestre (figuras compostas por colcheias e semicolcheias), variando a intensidade do som na execução, regidas por uma das professoras como um verdadeiro conjunto de câmara.

São essas algumas das situações registradas no caderno de campo (Madalozzo, 2019b) que evidenciam o envolvimento musical das crianças nas atividades realizadas ao longo do semestre nas aulas. Tendo em vista que os achados permitiram uma primeira compreensão do envolvimento como tendo um sentido musical e um sentido social para sua definição, em um segundo momento retornou-se a investigações da área da educação musical para procurar melhor conceituar esses sentidos do envolvimento. 
Em um primeiro conjunto de pesquisas analisadas, o envolvimento é associado ao engajamento, isto é, à disposição das crianças em participar das atividades, o que é demonstrado por sua atenção, sua concentração, sua curiosidade, a alegria e o prazer demonstrados naquilo que expressam musicalmente (Schünemann; Maffioletti, 2011; Soares, 2008). Em segundo, o envolvimento é entendido pela própria natureza da atividade musical das crianças, que engloba som, imagem, movimento e ação corporal, em uma forma múltipla de expressão inclusive nas propostas de escuta musical (Lino, 2010; Schroeder; Schroeder, 2011). Uma terceira definição diz respeito à participação do adulto como interlocutor do processo de vivência musical das crianças, enquanto responsável pela criação do envolvimento a partir das estratégias pedagógicas de que lança mão na gestão da aula de música (Russell, 2005; Santos, 2015). Porém, uma quarta definição de envolvimento, que extrapola as três anteriores, foi considerada a mais adequada para o caso desta investigação, porque está relacionada à autonomia musical das crianças nas aulas de musicalização.

Santos (2015) entende a musicalização como um processo educativo, mas também um espaço de prática social que ocorre por meio das interações dos pares e dos adultos, os responsáveis pela manutenção do respeito à produção infantil nesse espaço. Brito (2009) menciona a necessidade do reconhecimento e do respeito do professor sobre o modo musical das crianças, que reinventam relações e sentidos com o mundo sonoro em seu entorno em uma atitude mútua de troca, contato, afeto e construção colaborativa. Ilari (2018) discute a música no dia a dia das crianças como parte de uma complexa matriz social e pedagógica em que elas são agentes do seu próprio ambiente musical, cabendo ao professor observar e escutar continuamente as expressões da criança na e pela música. Niland (2009) utiliza a ideia do jogo musical, em que as crianças se envolvem corporal, vocal, social, cognitiva, emocional e criativamente; isto é, diferentes formas do brincar, o que deve ser entendido pelo professor como o modo natural de manifestação musical das crianças.

Esses entendimentos evidenciam uma complexa maneira de se definir o envolvimento musical das crianças na musicalização, enquanto forma de interação e relação com a música, mas também na atitude do professor ao compreender, dialogar, respeitar a autonomia e a produção musical das crianças, valorizando e impulsionando a relação com o mundo musical à sua volta em maneiras próprias de contribuir com o jogo musical criAtivo (ativo e criativo) o que acaba por levar à aprendizagem, que é o objetivo da formação musical. Em suma, o envolvimento das crianças com música está associado à construção de um olhar e de uma escuta atentos do professor em respeito à autonomia, à criAtividade, à expressão e à produção musical da e pela criança. 


\section{CONSIDERAÇÕES FINAIS (OU INICIAIS?) E IMPLICAÇÕES PARA A EDUCAÇÃO MUSICAL INFANTIL}

A etapa final da investigação é o momento da trama, da ressignificação de conceitos. Se por um lado a observação inicial dos achados em campo e da teoria sobre o envolvimento musical guiou a investigação para a emergência de sentidos musicais e sociais do envolvimento musical na musicalização infantil, um retorno a estudos específicos da área da educação musical permitiu a definição dos conceitos de criAtividade e de autonomia musical da criança, complementando o entendimento dos sentidos musicais e sociais do envolvimento musical.

A criAtividade diz respeito ao modo como as crianças interagem com o material sonoro e musical nas aulas, sendo protagonistas de suas construções e entendimentos do rico mundo sonoro ao seu redor. A autonomia musical é percebida pelo olhar dos professores na mediação dessa relação das crianças com a música, ao promoverem um ambiente de fomento à produção musical das crianças.

As definições de criAtividade e de autonomia musical são tão intrincadas que, em última análise, foi preciso reintegrá-las. Se o exame dos achados no campo empírico abriu espaço para uma segmentação analítica (sentidos musicais e sociais; criAtividade e autonomia musical), nessa etapa final é possivel reatar tais conceitos, admitindo que o envolvimento das crianças na musicalização se dá em um processo em que os aspectos musicais e sociais, na realidade, são dois lados de uma mesma moeda. A imagem da Cinta de Moëbius (1865) ilustra esse conceito: há apenas uma superfície que, pela ilusão de ótica, parece ter dentro e fora (Figura 2). A criAtividade, percebida pelo olhar do adulto-professor nas aulas de musicalização, faz sentido a partir da análise de aspectos musicais construídos nas interações entre as crianças e o rico ambiente musical com o qual se envolvem. Já a autonomia musical das crianças, em seu modo de expressão criAtivo, faz sentido pelas relações sociais construídas na musicalização entre seus pares e os adultos-professores.

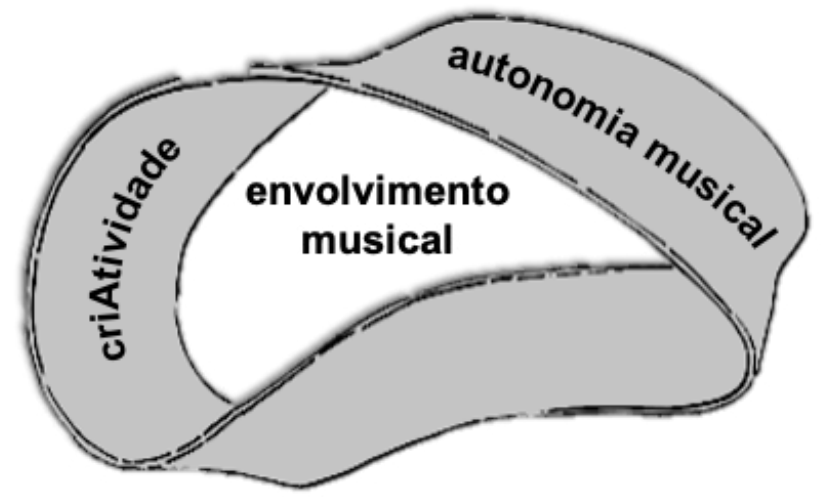

Figura 2: Representação dos aspectos musicais e sociais do envolvimento musical.

Fonte: adaptado de Madalozzo (2019b). 
Analisando os dados obtidos no levantamento no campo empírico em diálogo com aqueles vindos da reflexão teórica, conclui-se que a compreensão do envolvimento musical das crianças se dá a partir de um olhar transversal para os agentes envolvidos na musicalização infantil: a música ganha papel de destaque enquanto as crianças e os professores jogam com ela, e jogam-se nela, de maneira criAtiva.

Esses conceitos indicam possibilidades de criação e de manutenção de um clima de envolvimento nas aulas, que em última análise evidenciam dois importantes resultados: a paixão expressa pelas crianças por música e um significativo processo de aprendizagem, que são frutos de seu envolvimento com as práticas de musicalização infantil.

Como implicação dessas considerações para a área da educação musical, esta investigação procurou ampliar a reflexão sobre as práticas realizadas na musicalização infantil. A definição dos conceitos de criAtividade e de autonomia musical como sentidos musicais e sociais do envolvimento das crianças permite compreender que a musicalização vai além de metodologias de ensino de música, incluindo a construção de um olhar do adulto-professor em relação às crianças, como criAtivas agentes de construção de seu mundo musical.

\section{REFERENCIAS}

ANDRÉ, Marli E. D. A. de. Etnografia da prática escolar. 18. ed. Campinas: Papirus, 2012.

BRITO, Teca A. de. Música. In: BRASIL. Ministério da Educação. Secretaria de Educação Fundamental. Referencial curricular nacional para a educação infantil. Brasília: MEC/SEF, 1998. v. 3, p. 45-79.

Por uma educação musical do pensamento: educação musical menor. Revista da Abem, Porto Alegre, v. 17, n. 21, p. 25-34, mar. 2009.

CLIFFORD, James. Sobre a autoridade etnográfica. In: CLIFFORD, James. A experiência etnográfica: antropologia e literatura no século XX. 4. ed. Rio de Janeiro: Ed. UFRJ, 2011. p. 17-58.

CORSARO, William A. Young children's conception of status and role. Sociology of Education, [s. l.], v. 52, n. 1, p. 46-59, Jan. 1979.

Sociologia da infância. 2. ed. Porto Alegre: Artmed, 2011. p. 127-152.

DELALANDE, François. La musique est um jeu d'enfant. Paris: Buchet/ Chastel, 1984.

EZPELETA, Justa; ROCKWELL, Elsie. Pesquisa participante. 2. ed. São Paulo: Cortez, 1989. 
FERREIRA, Maria Manuela M. "A gente gosta é de brincar com os outros meninos!": relações sociais entre crianças num Jardim de Infância. Porto: Afrontamento, 2004.

FONTERRADA, Marisa T. O. De tramas e fios: um ensaio sobre música e educação. 2. ed. São Paulo: Ed. Unesp, 2008.

GAINZA, Violeta. Ocho estudios de psicopedagogia musical. Buenos Aires: Paidós, 1982.

La educación musical entre dos siglos: del modelo metodológico a los nuevos paradigmas. Victoria: Universidad de San Andrés, 2003 (Documento de Trabajo n. 10).

ILARI, Beatriz. Scaramouche goes to preschool: the complex matrix of young children's everyday music. Early Childhood Education Journal, [s. l.], v. 46, n. 1, p. 1-9, 2018.

KOOPS, Lisa. Classroom management for early childhood music settings. General Music Today, [s. l.], v. 31, n. 3, p. 82-86, 2018.

LINO, Dulcimarta Lemos. Barulhar: a música das culturas infantis. Revista da Abem, Porto Alegre, v. 18, n. 24, p. 81-88, set. 2010.

MADALOZZO, Tiago. "Eu quero [ouvir] de novo!": um estudo do envolvimento de crianças de cinco anos na musicalização infantil. In: JORNADAS EM ESTUDOS DA CRIANÇA, 4., 2019, Braga. Livro de resumos [...]. Braga: Universidade do Minho, Instituto de Educação, 2019. p. 10.

A prática criativa e a autonomia musical infantis: sentidos musicais e sociais do envolvimento de crianças de cinco anos de idade em atividades de musicalização. 2019. Tese (Doutorado em Música) - Setor de Artes, Comunicação e Design, Universidade Federal do Paraná, Curitiba, 2019b. Disponivel em: https: / / acervodigital.ufpr.br/handle/1884/63394. Acesso em: 3 out. 2020

MARCHI, Rita de C. Pesquisa etnográfica com crianças: participação, voz e ética. Educação \& Realidade, Porto Alegre, v. 43, n. 2, p. 727-746, abr./jun. 2018.

MUSICALIZAÇÃO para crianças. Curitiba: Alecrim Dourado Formação Musical, 2019. Disponivel em: https://www.alecrimformacaomusical.com. br/info. Acesso em: 3 out. 2020.

NILAND, Amanda. The power of musical play: the value of play-based, childcentered curriculum in early childhood music education. General Music Today, [s. l.], v. 23, n. 1, p. 17-21, 2009.

PENNA, Maura. Música(s) e seu ensino. 2. ed. Porto Alegre: Sulina, 2008. 
PENNA, Maura. Construindo o primeiro projeto de pesquisa em educação e música. Porto Alegre: Sulina, 2015.

PRESTES, Zoia Ribeiro. Quando não é quase a mesma coisa: análise de traduções de Lev Semenovitch Vigotski no Brasil - repercussões no campo educacional. 2010. Tese (Doutorado em Educação) - Faculdade de Educação, Universidade de Brasília, Brasília, 2010.

RUSSELL, Joan. Estrutura, conteúdo e andamento em uma aula de música na $1^{\text {a }}$ série do ensino fundamental: um estudo de caso sobre gestão de sala de aula. Revista da Abem, Porto Alegre, v. 13, n. 12., p. 73-88, mar. 2005.

SANTOS, Camila Marques dos. Culturas da infância na primeira infância: processos educativos em um projeto de musicalização infantil. 2015. Dissertação (Mestrado em Educação) - Centro de Educação e Ciência Humana, Universidade Federal de São Carlos, São Carlos, 2015.

SARMENTO, Manuel Jacinto. As culturas da infância nas encruzilhadas da $2^{\mathrm{a}}$ modernidade. In: SARMENTO, Manuel Jacinto; CERISARA, Ana Beatriz (orgs.). Crianças e Miúdos: perspectivas sociopedagógicas sobre infância e educação. Porto: Asa, 2004. p. 9-34.

SCHROEDER, Sílvia C. N.; SCHROEDER, Jorge L. As crianças pequenas e seus processos de apropriação da música. Revista da Abem, Londrina, v. 19, n. 25, p. 105-118, jul./dez. 2011.

SCHÜNEMANN, Aneliese T.; MAFFIOLETTI, Leda A. Música e histórias infantis: o engajamento da criança de 0 a 4 anos nas aulas de música. Revista da Abem, Londrina, v. 19, n. 26, p. 119-131, jul./dez. 2011.

SOARES, Cíntia V. S. Música na creche: possibilidades de musicalização de bebês. Revista da Abem, Porto Alegre, v. 16, n. 20, p. 79-88, set. 2008.

VIGOTSKI, Lev S. A formação social da mente: o desenvolvimento dos processos psicológicos superiores. 6. ed. São Paulo: Martins Fontes, 1998a.

Pensamento e linguagem. 2. ed. São Paulo: Martins Fontes, 1998b.

WALSH, Daniel J. Geração de dados. In: GRAUE, M. Elizabeth; WALSH, Daniel J. Investigação etnográfica com crianças: teorias, métodos e ética. Lisboa: Calouste Gulbenkian, 2003. p. 115-156. 
Tiago Madalozzo é doutor em Música e licenciado em Música pela Universidade Federal do Paraná (UFPR). É professor adjunto do curso de Licenciatura em Música da Universidade Estadual do Paraná - campus de Curitiba II (Unespar). Desenvolve estágio pós-doutoral no Programa de Pós-Graduação em Educação da UFPR, na Linha de Pesquisa em Linguagem, Corpo e Estética na Educação, com investigação sobre a audição musical ativa na infância. Foi professor de musicalização infantil na escola Alecrim Dourado Formação Musical e no Curso de Musicalização Infantil da UFPR, em Curitiba. Atua na capacitação de professores e na pesquisa em educação musical, com interesse nas áreas de educação musical infantil, educação musical na escola e audição musical ativa. É membro do corpo editorial do International Journal of Music in Early Childhood e pesquisador do Grupo de Pesquisa Arte, Educação e Formação Docente - GAEFO (Unespar) e do Núcleo de Estudos e Pesquisas em Infância e Educação Infantil - NEPIE (UFPR). https://orcid.org/0000-0002-0799-0719 